\title{
SIMULASI NUMERIK PADA ALIRAN AIR TANAH MENGGUNAKAN COLLOCATION FINITE ELEMENT METHOD
}

\author{
Ummu Salamah ${ }^{1, *}$, Annisa Aditsania ${ }^{2}$, P. H. Gunawan ${ }^{3}$ \\ ${ }^{1}$ Program Studi Ilmu Komputasi, Universitas Telkom [Email: salamah@students.telkomuniversity.ac.id] \\ ${ }^{2}$ Program Studi Ilmu Komputasi, Universitas Telkom [Email: aaditsania@telkomuniversity.ac.id] \\ ${ }^{3}$ Program Studi Ilmu Komputasi, Universitas Telkom [Email: phgunawan@telkomuniversity.ac.id] \\ *Corresponding Author
}

\begin{abstract}
This research presents a numerical simulation on groundwater flow using collocation finite element method (CFEM). Groundwater flow is known as the flow of water beneath the soil. Generally, groundwater flow is generated due to high hydraulic differences. The CFEM is an approximation solution of the differential equation by assuming the selected analytical function to fulfill the differential equation and setting the residual value turn out zero. Here, this research will discuss the case of groundwater flow on steady state and unsteady state. The results of numerical method CFEM is shown second order in terms of convergence by error. The numerical error in case of constant water flow is obtain $3.62 E-23$ using the grid size 6.1797e-07. Moreover, the flow of groundwater is simulated in various of hydraulic conductivity constants.
\end{abstract}

Keywords: collocation, FEM, groundwater, steady, unsteady.

\section{PENDAHULUAN}

Air tanah merupakan salah satu sumber daya alam yang paling berharga meskipun banyak yang tidak pernah melihatnya. Air mengalir melalui media berpori seperti batuan yang memiliki porositas dan permeabilitas yang berbeda. Salah satu media berpori yakni tanah, yang mempunyai daya resapan air tiggi (Waspodo (2002)).

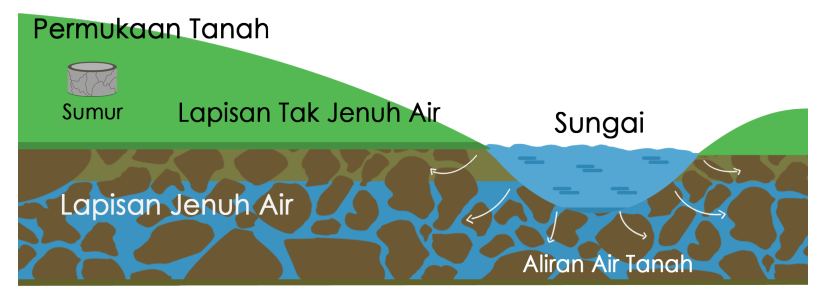

Gambar 1. Ilustrasi lapisan jenuh dan tak jenuh air tanah.

Air tanah yakni semua air yang berada di bawah permukaan tanah(Bear, Jacob dan Cheng (2010)), mengalirnya air di dalam tanah (groundwater flow) dikarenakan adanya perbedaan tinggi hidraulik di dalam tanah. Zona air tanah terbagi menjadi dua yaitu zona saturasi/lapisan jenuh air merupakan lapisan tanah yang seluruh ruang porinya terisi penuh oleh air. Sedangkan zona aerasi/lapisan tak jenuh air adalah lapisan tanah yang sebagian ruang porinya terisi oleh air, selebihnya terisi oleh udara. Lapisan jenuh dan tak jenuh air dibatasi oleh muka air tanah. Penjelasan di atas dapat diilustrasikan pada Gambar 1 .

Dalam makalah ini, simulasi digunakan untuk memprediksi letak berkumpulnya air dan tepat atau tidaknya metode Collocation finite element digunakan untuk simulasi aliran air tanah (Segerlind, Larry J dan Saunders (1987)). Metode finite element yang digunakan yakni Collocation finite element akan menghampiri persamaan aliran air tanah dalam satu dimensi (1D) persama.annya sebagai 
berikut :

$$
S_{s} \frac{\partial h}{\partial t}=K\left(\frac{\partial^{2} h}{\partial x_{i}, \partial x_{i}}\right)
$$

dengan $S_{S}$ adalah specific storage (nilai ini didapatkan dengan membagi koefisien penyimpanan dengan ketebalan akuifer), $K$ adalah konduktivitas hidrolik, $h$ adalah tinggi air tanah $(m)$ dan $t$ adalah waktu $(s)$.

Aliran air tanah akan dihampiri dengan solusi CFEM karena persamaan CFEM memiliki orde yang tinggi. Selain itu, CFEM memiliki kelebihan proses komputasi yang cepat (Schillinger, Dominik dan Evans et al. (2015)). Tujuan pada penelitian ini untuk mensimulasikan CFEM pada kasus aliran air tanah. Serta simulasi pada unsteady state lalu membandingkan solusi numerik dan solusi analitiknya dengan metode separasi variabel, tambahan lain yang ingin dilihat yakni konvergensi solusi numerik.

\section{Unsteady Collocation Finite Element Method}

Metode collocation adalah salah satu anggota dari residual methods (Meenal, Mategaonkar dan Eldho (2012)). Pada collocation, bentuk formula yang digunakan hanya untuk steady state yakni nilai $t$ diabaikan sehingga persamaannya sebagai berikut:

$$
\begin{aligned}
& y^{\prime \prime}(x)+Q y(x)=F ; \quad 0 \leq x \leq l \\
& y(0.0)=0 ; \quad y(1.0)=A,
\end{aligned}
$$

dengan $y$ adalah fungsi steady, $Q$ adalah konstanta dan $F=$ Fungsi.

Asumsikan fungsi berikut adalah solusi hampiran (2) sebagai berikut:

$$
\begin{aligned}
& y(x)=C_{1} x+C_{2} x(x-1)+C_{3} x^{2}(x-1) ; \\
& y^{\prime \prime}(x)=2 C_{2}+C_{3}(6 x-2),
\end{aligned}
$$

dengan $y_{i}(x)$ disebut sebagai trial functions yang dipilih. Nilai residual pada CFEM di- tentukan sebagai berikut:

$$
R(x)=y^{\prime \prime}+Q y-F=0
$$

Selanjutnya, substitusikan persamaan (4) pada persamaan (5) dan memilih nilai $x$ diantara $0 \leq x \leq 1$ dengan $\Delta x$ yang sama sehingga dipilih $x_{1}=1 / 3$ dan $x_{2}=2 / 3$. Setelah itu selesaikan persamaan (5) sesuai nilai $x$ yang dipilih, sehingga didapatkan sistem persamaan berikut ini:

$$
\begin{aligned}
& \left(2-\frac{2 Q}{9}\right) C_{2}-\left(\frac{2 Q}{27}\right) C_{3}=-\frac{Q A}{3}+F \\
& \left(2-\frac{2 Q}{9}\right) C_{2}+\left(2-\frac{4 Q}{27}\right) C_{3}=-\frac{2 Q A}{3}+F
\end{aligned}
$$

Lalu persamaan (6-7) dicari nilai $C$ yang akan disubstitusikan pada solusi CFEM dengan nilai $x$ yang telah dipilih sehingga didapat,

$$
y(x)=C_{1} x+C_{2} x(x-1)+C_{3} x^{2}(x-1) .
$$

Pada penelitian ini akan membahas kasus aliran air tanah yang memiliki bentuk persamaan (1) yang akan disimulasikan pada kondisi unsteady yakni nilai $t$ diperhatikan. Sehingga, metode collocation perlu adanya diskritisasi waktu pada persamaan (1) supaya serupa dengan persamaan (2). Penjelasan kasusnya sebagai berikut:

- Diskritisasi turunan terhadap $t$ pada persamaan (1), dengan parameter $h=y$.

$$
S_{s} \frac{y^{n+1}-y^{n}}{\Delta t}=K\left(y^{n+1}\right) "
$$

sehingga diperoleh persamaan unsteady state.

- Bentuk persamaan dengan persamaan 9 kedalam bentuk mirip steady (2) didapat,

$$
\left(y^{n+1}\right) "-\frac{S_{S}}{\Delta t K} y^{n+1}=-\frac{S_{s}}{\Delta t K} y^{n}
$$




\section{Simulasi Numerik}

Berikut akan dibahas mengenai analisi numerik seperti konvergensi galat sampai simulasi aliran air tanah.

\subsection{Solusi numerik dan solusi analitik}

Pada bagian ini dipaparkan simulasi numerik yang dibandingkan dengan solusi analitik menggunakan sparasi variabel. Bentuk solusi separasi variabel (Wazwaz (2002)), sebagai berikut:

$$
\begin{gathered}
\Psi(x, t)=\sum_{k=1}^{\infty} A_{k} \sin \left(\frac{k \pi x}{L}\right) e^{-\left(\frac{k \pi}{L}\right)^{2} \mu t} \\
\Psi(x, 0)=\sum_{k=1}^{\infty} A_{k} \sin \left(\frac{k \pi x}{L}\right)
\end{gathered}
$$

Adanya dua solusi yakni solusi hampiran terhadap solusi analitiknya, maka diperlukan analisis keakuratan yakni dengan menghitung nilai eror/galat. Menganalisis galat sangat penting di dalam perhitungan yang menggunakan metode numerik.

Galat berasosiasi dengan seberapa dekat solusi hampiran terhadap solusi sejatinya. Semakin kecil galatnya, semakin teliti solusi numerik yang didapatkan serta menganilisis konvergensi solusi numerik. Berikut diberikan rumus menghitung eror/galat,

$$
\text { Error }=\sum_{i}^{n}\left|\Psi_{i}-y_{i}\right| \Delta x
$$

dan konvergensi,

$$
\begin{aligned}
& \left(\frac{\| \text { Error }_{2} \|}{\| \text { Error }_{1} \|}\right)=\left(\frac{\Delta x_{2}}{\Delta x_{1}}\right)^{\tau}, \\
& \tau=\frac{\log \left(\| \text { Error }_{2}\|/\| \text { Error }_{1} \|\right)}{\log \left(\Delta x_{2} / \Delta x_{1}\right)} .
\end{aligned}
$$

Untuk melihat hasil perbandingan kedua solusi, maka kasus yang akan diselesaikan de- ngan parameter-parameter yang diberikan:

$$
\begin{aligned}
& h(x, 0)=\sin (\pi x), \quad x \in[0,1], \\
& h(0, t)=h(1, t)=0, \quad t>0, \\
& Q=1, \quad \mu=1, \quad L=1 .
\end{aligned}
$$

Maka solusi separasi variabel yang dihasilkan sebagai berikut:

$$
\Psi(x, t)=\sin (\pi x) e^{-\left(\pi^{2}\right) \mu t} .
$$

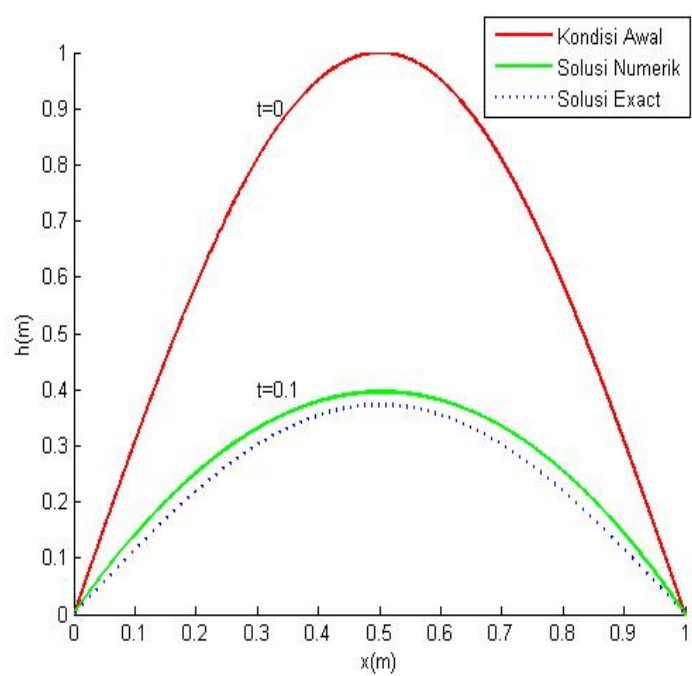

Gambar 2. Hasil simulasi solusi numerik dan solusi analitik dengan kondisi awal $\Psi(x, 0)=$ $\sin (\pi x)$.

Untuk kasus dengan nilai awal $\Psi(x, 0)=$ $\sin (\pi x)$ ternyata memiliki hasil yang serupa dengan solusi numeriknya yakni menggunakan metode Collocation finite element. Hal ini dapat dilihat pada Gambar 2 dan detail galat dapat dilhat pada Tabel 1 .

Pada Gambar 2 dan Tabel 1, nilai galat mengalami penurunan sebanding dengan $\Delta x$ yang menurun. Selebihnya, laju konvergensi $\tau$ yang dihasilkan memiliki nilai konvergensi $\tau \approx 2$. Nilai laju konvergensi yang didapatkan sesuai dengan orde turunan spatial dari persamaan (1). Meskipun dalam diskritisasi waktu (9), menggunakan first order forward difference, tidak mempengaruhi laju konvergensi yang mendekati nilai 2 .

Dengan persamaan yang sama, kasus lain perhitungan menggunakan separasi variabel yakni kondisi awal bukan berupa fungsi 
Tabel 1. Nilai galat solusi CFEM dengan solusi separasi variabel pada $t=0.1$ dengan kondisi awal $\Psi(x, 0)=\sin (\pi x)$.

\begin{tabular}{|c|c|c|c|}
\hline No. & $\Delta x$ & Error & $\tau$ \\
\hline 1 & $5.0508 \mathrm{e}-05$ & $4.1254 \mathrm{e}-09$ & - \\
2 & $1.6835 \mathrm{e}-05$ & $4.5811 \mathrm{e}-10$ & 2.0004 \\
3 & $5.5742 \mathrm{e}-06$ & $5.0891 \mathrm{e}-11$ & 2.0002 \\
4 & $1.8706 \mathrm{e}-06$ & $5.6542 \mathrm{e}-12$ & 2.0001 \\
5 & $6.1797 \mathrm{e}-07$ & $6.1710 \mathrm{e}-13$ & 2.0000 \\
\hline
\end{tabular}

melainkan berupa konstanta. Persamaan (1) dengan parameter-parameter berikut:

$$
\begin{aligned}
& h(x, 0)=1, \quad x \in[0,1], \\
& h(0, t)=h(1, t)=0, \quad t>0 ; \\
& Q=1, \quad \mu=1, \quad L=1 .
\end{aligned}
$$

Maka solusi separasi variabel yang dihasilkan sebagai berikut:

$$
\begin{aligned}
& \Psi(x, t)=\sum_{k=1}^{M} \frac{4}{k \pi} \sin (k \pi x) e^{-(k \pi)^{2} \mu t} ; \\
& k=\text { ganjil } ; \quad M \in \mathbb{N}
\end{aligned}
$$

Hasil perbandingan solusi numerik Collocation finite element method dengan separasi variabel diperlihatkan pada Gambar 3 dan nilai galat dapat dilihat pada Tabel 2. Menggunakan kondisi awal $\Psi(x, 0)=1$, nilai galat yang dihasilkan sangat kecil atau $E r r \rightarrow 0$ dan cenderung tetap sehingga solusi numerik dan analitiknya sama.

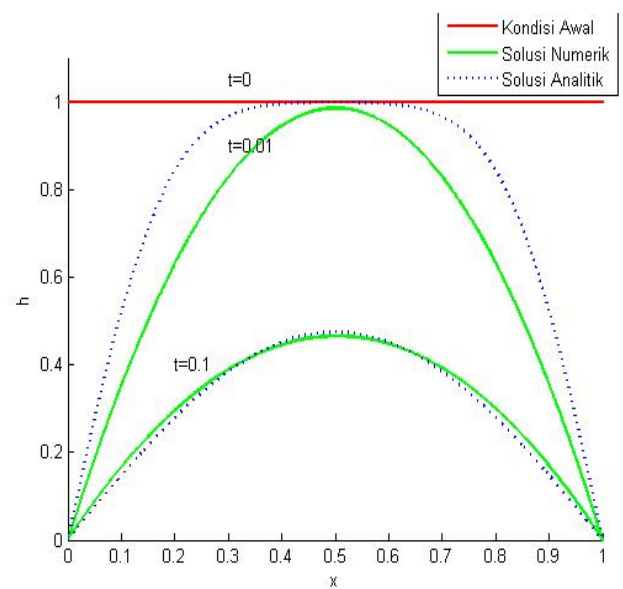

Gambar 3. Hasil simulasi solusi CFEM dan solusi analitik dengan $\Psi(x, 0)=1$.

Untuk mengetahui akurasi solusi numerik dengan analitik dapat dilihat pada galatnya, yang telah dihitung pada Tabel 2 .

Tabel 2. Nilai galat solusi CFEM dengan solusi separasi variabel pada $t=0.1$ engan kondisi awal $\Psi(x, 0)=1$.

\begin{tabular}{|c|c|c|}
\hline No. & $\Delta x$ & Error \\
\hline 1 & $5.0508 \mathrm{e}-05$ & $2.9364 \mathrm{e}-21$ \\
2 & $1.6835 \mathrm{e}-05$ & $9.7875 \mathrm{e}-22$ \\
3 & $5.5742 \mathrm{e}-06$ & $3.2625 \mathrm{e}-22$ \\
4 & $1.8706 \mathrm{e}-06$ & $1.0875 \mathrm{e}-22$ \\
5 & $6.1797 \mathrm{e}-07$ & $3.62 \mathrm{e}-23$ \\
\hline
\end{tabular}

\subsection{Simulasi aliran air tanah}

Pada bagian ini akan dibahas tentang simulasi numerik aliran tanah menggunakan collocation finite element. Dalam simulasi ini, situasi keadaan ketika air sungai secara tiba-tiba mengering sehingga adanya perbedaan tekanan air dalam tanah mengakibatkan adanya aliran air tanah. Ilustrasi penampang sungai dan air tanah dapat dilihat pada Gambar 4 .

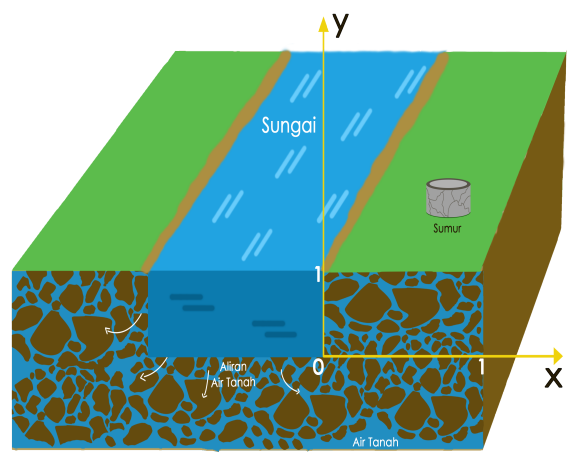

Gambar 4. Ilustrasi penampang air tanah dalam bentuk 3D.

Simulasi numerik untuk keadaan masalah ini dapat menggunakan kondisi sebagai berikut:

$$
\begin{aligned}
& h(x, 0)=1, \quad x \in[0, L], \\
& h(0, t)=0, \quad h(L, t)=1, \quad t>0, \\
& S_{s}=1, \quad K=1, \quad L=1 .
\end{aligned}
$$

Gambar 6 menampilkan pengaruh nilai konduktivitas hidrolik $K=0.7$ dan $S_{s}=$ 1 (konstan) dimana pada $K=0.7$ hasil penurununan tinggi air $(h)$ paling cepat disaat $t=0.01$ menuju $t=0.02$, tetapi saat $t=0.02$ 


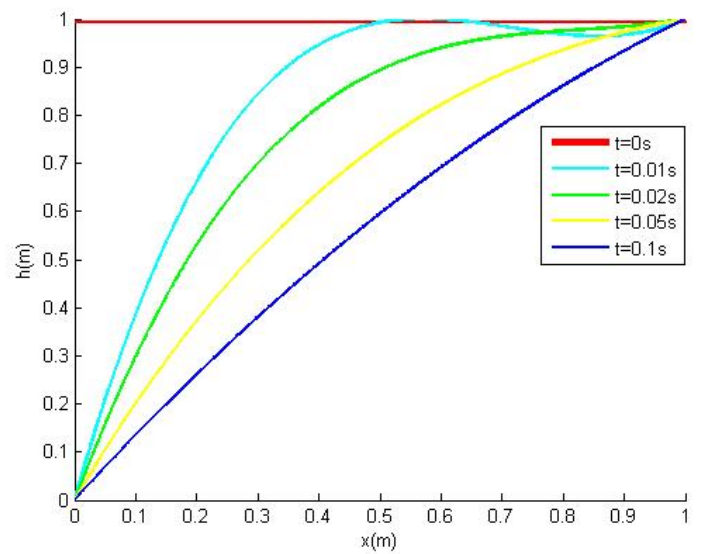

Gambar 5. Simulasi groundwater flow dengan CFEM dan parameter $K=1$ dan $S_{s}=1$.

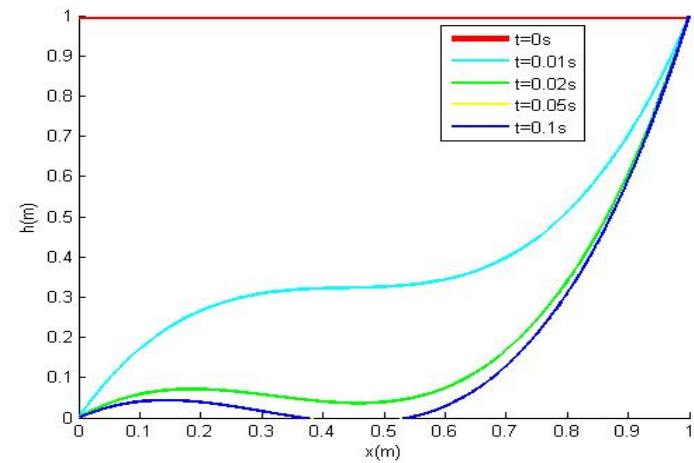

Gambar 6. Simulasi groundwater flow dengan CFEM dan parameter $K=0.7$ dan $S_{s}=$ 1 .

menuju $t=0.05$ mengalami penurunan tinggi air yang relatif lebih lambat.

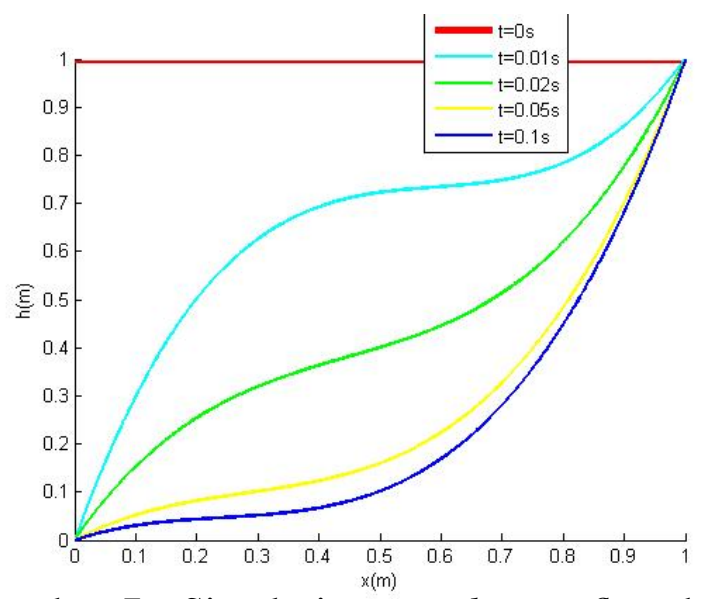

Gambar 7. Simulasi groundwater flow dengan CFEM dan parameter $K=0.9$ dan $S_{s}=$ 1 .

Gambar 7 menampilkan pengaruh nilai konduktivitas hidrolik $K=0.9$ dan $S_{s}=$ 1 (konstan) dimana pada $K=0.9$ hasil penurununan tinggi air besar disaat $t=0.01$ menuju $t=0.02$ dan saat $t=0.02$ menuju $t=0.05$, tetapi disaat $t=0.05$ menuju $t=0.1$ me- ngalami penurunan tinggi air yang relatif lebih lambat.

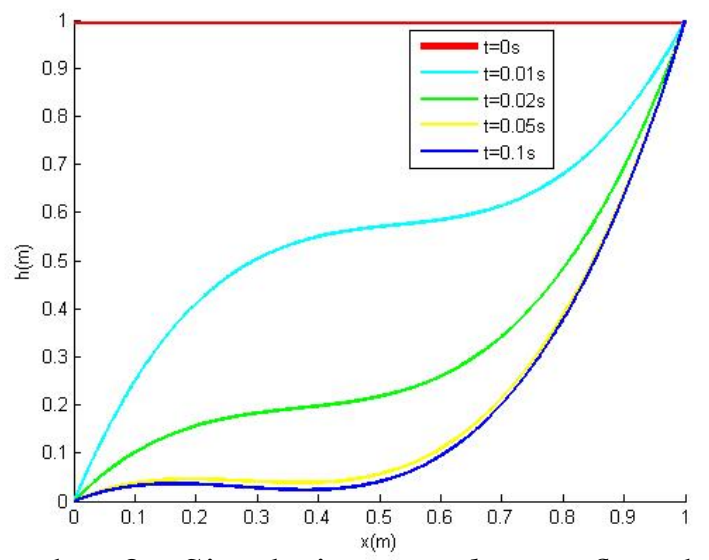

Gambar 8. Simulasi groundwater flow dengan CFEM dan parameter $K=1$ dan $S_{s}=$ 1.2 .

Gambar 8. menampilkan pengaruh nilai Spesific storage, dengan nilai $K=1$ (konstan) dan $S_{s}=1.2$ dimana pada $S_{s}=1.2$ hasil penurununan volume air besar disaat $t=0.01$ menuju $t=0.02$ dan saat $t=0.02$ menuju $t=0.05$, tetapi disaat $t=0.05$ menuju $t=0.1$ mengalami penurunan volume air yang relatif sangat lambat.

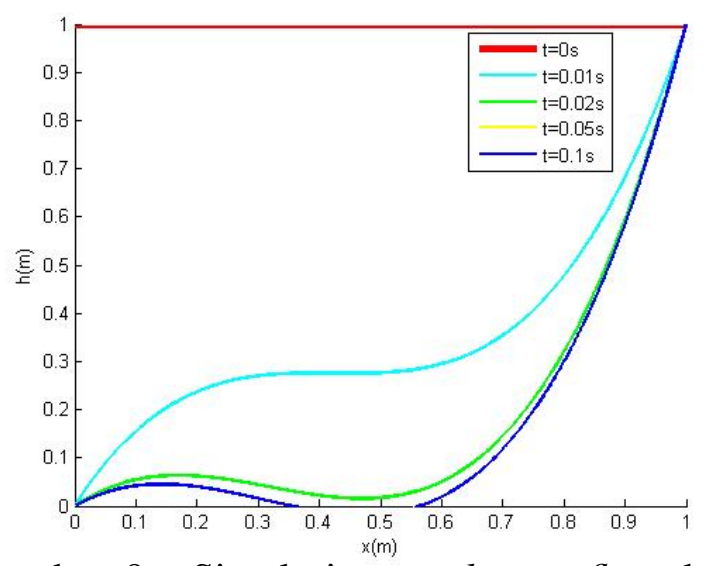

Gambar 9. Simulasi groundwater flow dengan CFEM dan parameter $K=1$ dan $S_{s}=$ 1.5.

Gambar 9. menampilkan pengaruh nilai Spesific storage, dengan nilai $K=1$ (konstan) dan $S_{s}=1.5$ dimana pada $S_{s}=1.5$ hasil penurununan volume air besar disaat $t=0.01$ menuju $t=0.02$ dan saat $t=0.02$ menuju $t=0.05$, tetapi disaat $t=0.05$ menuju $t=0.1$ mengalami penurunan volume air yang relatif sangat lambat. 
Tabel 3. Simulasi groundwater flow pada $x=$ 0.3 dengan $K$ yang berbeda.

\begin{tabular}{|c|c|c|c|c|c|}
\hline No. & $K$ & $S_{S}$ & $\mathrm{~h} 1$ & $\mathrm{~h} 2$ & $\mathrm{~h} 3$ \\
\hline 1 & 0.7 & 1 & 0.3 & 0.05 & 0.01 \\
2 & 0.9 & 1 & 0.67 & 0.3 & 0.08 \\
\hline
\end{tabular}

Pada Tabel 3 dan Tabel 4 menyatakan $h 1$ adalah tinggi air saat $t=0.01, h 2$ adalah tinggi air saat $t=0.02$ dan $h 3$ adalah tinggi air saat $t=0.05$.

Dari hasil simulasi pada Tabel 3 dan 4, dilihat bahwa nilai konduktivas hidrolik $(K)$ sangat berpengaruh. Semakin besar $K$ semakin cepat penurunan tinggi airnya hal ini sesuai dengan pengertian konduktivitas hidrolik yakni kecepatan air mengalir. Pada tabel-tabel tersebut didapatkan, untuk nilai $K=0.7$ saat $t=0.01$ tinggi air $h=0.3$ mengalami penurunan menjadi $h=0.05$ saat $t=0.02$. Untuk nilai $K=0.9$ penurunan air lebih cepat dibandingkan dengan nilai $K=0.7$ yakni, saat $t=0.01$ tinggi air $h=0.67$ menjadi $h=0.3$ saat $t=0.02$.

Tabel 4. Simulasi groundwater flow dengan $S_{S}$ yang berbeda.

\begin{tabular}{|c|c|c|c|c|c|}
\hline No. & $K$ & $S_{s}$ & $\int_{0}^{1} h 1$ & $\int_{0}^{1} h 2$ & $\int_{0}^{1} h 3$ \\
\hline 1 & 1 & 1.2 & 0.5464 & 0.4219 & 0.2564 \\
2 & 1 & 1.5 & 0.3519 & 0.2394 & 0.1642 \\
\hline
\end{tabular}

\section{KESIMPULAN}

Berdasarkan hasil pengujian dan analisis yang dilakukan maka kesimpulannya, solusi numerik Collocation finite element method dapat menghampiri persamaan aliran air tanah dengan baik. Hal ini dibuktikan dengan nilai galat rata-rata yang dihasilkan adalah $8.77 e-24$ dan konvergensinya mendekati 2 atau second order. Simulasi aliran air tanah dipengaruhi oleh nilai konduktivitas hidrolik dan spesific storage. Selisih penurunan volume air dengan parameter $S_{s}=1.5 \mathrm{da}$ ri $t=0.02$ menuju $t=0.05$ adalah 0.0752 . Sedangkan, menggunakan parameter $S_{s}=1.2$ diwaktu $t=0.02$ menuju $t=0.05$ memiliki selisih sebesar 0.1655 .

\section{Daftar Pustaka}

Bear, Jacob dan Cheng, A. H.-D. (2010). Modeling groundwater flow and contaminant transport, volume 23. Springer Science \& Business Media.

Meenal, Mategaonkar dan Eldho, T. (2012). Simulation-optimization model for groundwater contamination remediation using meshfree point collocation method and particle swarm optimization. Sadhana, 37(3):351-369.

Schillinger, Dominik dan Evans, J. A., Frischmann, F., Hiemstra, R. R., Hsu, M.-C., and Hughes, T. J. (2015). A collocated c0 finite element method: Reduced quadrature perspective, cost comparison with standard finite elements, and explicit structural dynamics. International Journal for Numerical Methods in Engineering, 102(34):576-631.

Segerlind, Larry J dan Saunders, H. (1987). Applied finite element analysis.

Waspodo, R. S. B. (2002). Permodelan aliran airtanah pada akuifer tertekan dengan menggunakan metoda beda hingga (finite difference method) di kecamatan kertajati, kabupaten majalengka. Jurnal Keteknikan Pertanian, 16(1).

Wazwaz, A.-M. (2002). Partial differential equations. CRC Press. 